\title{
PERAN NEGARA HUKUM INDONESIA MELINDUNGI RAKYATNYA DALAM MENYAMBUT MASYARAKAT EKONOMI ASEAN (MEA) 2015
}

\author{
Yuswanto \\ Wakil Dekan 1 Fakultas Hukum Universitas Lampung \\ e-mail: yuswantounila@yahoo.co.id
}

\begin{abstract}
Indonesia is a sovereign country. Sovereign does not only mean "denotation"; which is the state has the power of government that is not subject to other state power. Implementation of the state intended to realize the people's welfare. If it is associated to the competition with other countries, then, we will know more about the role of the state in protecting its citizens in order to avoid "homo homini lupus" as what Hobbes said. So, this is the challenge of the welfare state, wherein it should not fail. The existence of state failure cases in providing protection for its citizens, especially in free trade has become a scourge for the people. Those people who are not able to compete in free trade, in the end, they will only be a spectator and do not have any role in AEC 2015. State efforts to protect people among others: increasing competitiveness and export volume, then, prioritizing the use of the goods / services in the country. In the regulation, it needs to set rules on the security measures of domestic products and supervision over circulation of goods and services, and by applying the Early Warning System to the possibility of a surge in imports.
\end{abstract}

Keywords: Sovereign, Welfare State, Competitiveness, ASEAN Economic Community 2015

\section{abstrak}

Indonesia adalah negara yang berdaulat. Kata berdaulat di sini tidak saja bermakna denotatif bahwa negara memiliki kekuasaan pemerintahan yang tidak tunduk pada kekuasaan negara lain. Penyelenggaraan negara dimaksudkan untuk mewujudkan kesejahteraan rakyat. Bila dikaitkan dengan persaingan dengan negara lain, maka dapat ditarik lagi tentang peran negara dalam melindungi warganya agar tidak terjadi apa yang menurut Hobbes sebagai "homo homini lupus". Inilah tantangan negara kesejahteraan tersebut, di mana negara tidak boleh gagal. Adanya kasus-kasus tentang gagalnya negara dalam memberikan perlindungan bagi warganya, terutama dalam perdagangan bebas telah menjadi momok bagi rakyat. Rakyat yang tidak mampu bersaing dalam perdagangan bebas, pada akhirnya hanya menjadi penonton dan tidak memainkan peranan dalam MEA 2015. Upaya 
negara dalam melindungi rakyat antara lain dengan meningkatkan daya saing, meningkatkan volume ekspor, mengutamakan penggunaan barang/ jasa dalam negeri. Di bidang regulasi, perlu ditetapkan peraturan tentang tindakan pengamanan produk dalam negeri dan pengawasan terhadap barang beredar dan jasa, serta dengan menerapkan Early Warning System terhadap kemungkinan terjadinya lonjakan impor.

Kata Kunci: Berdaulat, Negara Kesejahteraan, Daya Saing, MEA 2015

\section{A. Pendahuluan}

Indonesia adalah negara yang berdaulat. Kata berdaulat di sini tidak saja bermakna denotatif bahwa negara memiliki kekuasaan pemerintahan yang tidak tunduk pada kekuasaan negara lain, tetapi terselubung juga makna konotatif tentang "giliran" kekuasaan. Cita-cita kedaulatan telah dicapai melalui proses Proklamasi Kemerdekaan, sehingga jelas sudah demarkasi politik hukum kolonial menuju politik hukum nasional. Negara kesejahteraan (welfare state) sebagai antitesa dari konsep negara penjaga malam, pasti punya tujuan. Negara mempunyai kewajiban untuk memenuhi (fulfill), menyediakan (provide), melayani (service) dan melindungi (protect) warga negaranya. Kesemua itu kemudian direduksi dan diintroduksi dalam konsep hak asasi manusia (HAM), baik Sipol, maupun Ekosob, berupa hak bebas dari (free from) dan bebas untuk (free to). Hak untuk bebas dari rasa takut/ancaman dan bebas untuk mendapatkan kehidupan layak, misalnya, dapat dikategorikan ke dalamnya. Bila dikaitkan dengan persaingan dengan negara lain, maka dapat ditarik lagi tentang peran negara dalam melindungi warganya agar tidak terjadi apa yang menurut Hobbes sebagai "homo homini lupus". Inilah tantangan negara kesejahteraan itu.

Dikaitkan dengan konteks perdagangan bebas, maka di dalamnya setiap negara bersaing dalam pengembangan ekonomi melalui perdagangan. Pelaksanaan perdagangan bebas dilaksanakan dalam kawasan regional tertentu, termasuk di kawasan negara ASEAN. Masyarakat Ekonomi ASEAN (MEA) yang akan diterapkan di akhir 2015 perlu dipersiapkan agar Indonesia dapat bersaing di dalamnya. Konteks yang terkandung dalam MEA 2015 adalah konteks pasar bebas yang di dalamnya "diharamkan" sekat-sekat yang dapat menghambat perdagangan, atau dalam konteks yang lebih luas, tidak boleh ada halangan (barrier) di bidang ekonomi. Dunia menjadi satu tanpa sekat (borderless). Indonesia mau tidak mau harus mengambil porsi paling besar dalam MEA 2015. Hal ini merupakan keniscayaan, karena Indonesia merupakan negara demokratis terbesar di ASEAN dengan 240 juta penduduk. Apalagi, sejarah mencatat bahwa

\footnotetext{
${ }^{1}$ Secara kebahasaan, kata "daulat" dapat diartikan dengan "giliran", "orde"
} 
Indonesia adalah salah satu dari lima negara pendiri ASEAN di Tahun 1967. Terhitung ada 10 (sepuluh) negara yang tergabung dalam ASEAN, termasuk Kamboja yang bergabung di Tahun 2009.

Maksud didirikannya ASEAN adalah untuk menyepakati kerjasama bidang ekonomi. Diawali dengan kesepakatan Preferential Tariff Arrangement (PTA) pada Tahun 1977. Salah satu kesepakatan yang menjadi cikal bakal visi pembentukan ASEAN Economic Community (AEC) 2015 atau MEA 2015 adalah disepakatinya Common Effective Preferential Tariff - ASEAN Free Trade Area (CEPT-AFTA) pada Tahun 1992 dengan target implementasi semula Tahun 2008.

Peran ASEAN juga menjadi begitu penting dan dunia begitu berkepentingan terhadap negara-negara di kawasan ASEAN. Globalisasi ekonomi dunia telah menggiring (kalau tidak mau menggunakan istilah "diseret") negara-negara ASEAN—termasuk Indonesia-di dalamnya ke dalam area pasar bebas (free trade area). Dunia rimba perdagangan yang menuntut kesiapan setiap negara apabila ia tidak mau menjadi mangsa negara-negara maju (developed country). Apabila dikaitkan dengan teori kedaulatan negara, menurut penulis, di sini telah terjadi sesuatu yang kontradiktif. Di satu sisi Indonesia-dan negara-negara lain-merupakan negara berdaulat, namun di sisi lain, negara-negara berdaulat tersebut tidak dapat "melawan" konsensus bernama perdagangan bebas.

Dunia memiliki kepentingan begitu besar terhadap negara di kawasan ASEAN. Indikasi akan hal ini dapat dilihat dari penerapan ASEAN Free Trade Agreement (AFTA) disepakati 1992 dan mulai diterapkan Tahun 2002. Sejak Januari 2010 ASEAN-6 menghapus seluruh tarif pada kategori "Inclusion List". Dengan demikian, sejak 2010, tidak ada lagi hambatan perdagangan di negara ASEAN. ${ }^{2}$ Pada tahun 2010, 99,11\% tariff ASEAN-6 adalah 0\%, dan 98,86\% tarif ASEAN-4 berada di kisaran 0-5\%. Kerangka kerjasama perdagangan barang, jasa dan investasi telah berjalan sejak 1990an: CEPT-AFTA 1992; ASEAN Framework Agreement on Services (AFAS, 1995) dan ASEAN Investment Area (1998). ${ }^{3}$ Bahkan, sentralisme kawasan ASEAN kemudian diperluas menuju regionalisme yang mencakup juga peningkatan daya saing ASEAN dengan RRT dan India.

Kondisi di atas sejalan dengan Visi ASEAN 2020 (ASEAN Vision 2020), yaitu: "A stable, prosperous, and highly competitive region with equitable economic development, and reduced poverty and socio-economic disparities." " Target Tahun 2020 tersebut kemudian dipercepat

\footnotetext{
${ }^{2}$ Direktorat Kerjasama ASEAN Kemendag RI, "Kesiapan Indonesia Memasuki Masyarakat Ekonomi ASEAN di 2015”, Presentasi dibawakan di Hotel Aryaduta, Jakarta, 13 Desember 2010.

${ }^{3}$ Ibid.

${ }^{4}$ ASEAN Summit, Kuala Lumpur, Desember 1997.
} 
pencapaiannya di Tahun 2015 yang disetujui pada Forum ASEAN SUMMIT 2007. Serangkaian persetujuan menuju MEA 2015 juga dilakukan di Bali melalui Bali Concord II 2003, dengan isu ASEAN Economic Community: "free flows of goods, services, investment, skilled labor and freer flow of capital" no later than 2020. Target yang hendak dicapai mencakup beberapa isu pokok, seperti: pertanian dan hutan; kompetisi perdagangan; perlindungan konsumen; HKI; energi; transportasi; pariwisata; pengembangan UKM; dan konektifitas negara ASEAN.

Penerapan MEA 2015 memerlukan strategi dan kesiapan, sedangkan kondisi infrastruktur Indonesia masih buruk. Data-data yang berisi; jalanraya $34.000 \mathrm{~km}$, sebagian besar peninggalan jaman Belanda; jalan tol hanya $1,82 \%$ dari total jalan raya; neraca listrik PLN defisit $10,95 \mathrm{GW}$; rasio panjang jalan dan jumlah pelabuhan adalah $4.500 \mathrm{~km} /$ pelabuhan patut menjadi pertimbangan. Rumusan permasalahan yang menjadi pokok tulisan ini adalah: 1) Bagaimana dengan konsep pendirian negara Indonesia yang bercita-cita menyejahterakan warganya disandingkan dengan MEA 2015?; dan 2) Apakah globalisasi yang telah memaksa setiap negara untuk memasuki area perdagangan bebas tidak bertentangan dengan konsep negara kesejahteraan?

\section{B. Metode Kajian}

Metode yang dipakai dalam kajian ini adalah metode yang lazim dipakai dalam penelitian ilmu hukum, yaitu metode penelitian ilmu hukum. Pendekatan yang dipakai adalah pendekatan perundang-undangan, yaitu dengan melakukan analisis terhadap peraturan perundang-undangan. Metode pendekatan ilmu hukum dogmatik juga dipakai untuk menelusuri konsepkonsep tentang negara, kedaulatan negara, dan kesejahteraan rakyat.

\section{Pembahasan}

\section{Kedaulatan dan Berdaulat}

Kata kedaulatan dalam literatur berbahasa Inggris dipadankan dengan kata "souvereignty" yang dalam Black's Law Dictionary diberi pengertian:

"The supreme, absolute, and uncontrollable power by which any independent state is governed; supreme political authority; paramount control of the constitution and frame of government and its administration; the self-sufficient source of political power, from which all specific political powers are derived; the international independence of a state, combined with the right and power of regulating its internal affairs without foreign dictation; 
also a political society, or state, which is sovereign and independent." 5

Titik tekan pengertian souvereignty adalah pada kekuasaan tertinggi, mutlak, dan tidak dibawah kendali (uncontrollable) yang dengannya setiap negara merdeka mejalankan pemerintahannya. Termasuk dalam pengertian kedaulatan (souvereignty)—dalam kaitannya dengan hubungan internasional-adalah bahwa setiap negara berdaulat memiliki hak dan kewenangan untuk membentuk peraturan dalam negeri yang tidak dapat didikte oleh negara lain (without foreign dictation). Dengan demikian, kedaulatan merupakan puncak kewenangan, sehingga tidak ada kekuasaan lain yang lebih besar dan dapat mempengaruhi negara yang berdaulat. Berdaulat artinya bebas menentukan pilihan, dalam konteks ini adalah bebas bergabung dengan MEA 2015, AFTA 2010, atau dalam kerjasama internasional apapun. Tetapi, apakah kita benar-benar berhak memilih, sementara setiap negara - termasuk Indonesia—juga terikat tata pergaulan negara-negara?

Negara yang tidak mampu menjalankan kedaulatannya dapat dikategorikan kegagalan negara (state failure). Bila hal ini telah terjadi, maka indikasinya adalah bahwa ada kesalahan serius pada negara tersebut. Tentu saja setiap negara tidak dapat steril dengan cara mengisolasikan diri dari tatangan pergaulan negara-negara di dunia. Setiap negara memiliki posisi masing-masing terhadap hukum internasional dan segala aturannya. Gerard Kreijen memberikan ilustrasi yang menarik akan hal ini dalam mengantar bukunya:

Since this is a legal study, this section gives a basic account of the State within modern international law and order. This account is to serve as a 'value neutral' treatment of the State, statehood, and some of the legal concepts and principles related thereto. It facilitates the subsequent discussion - in section 3 - of two essentially different conceptions of the State that one may hold according to one's view of international law as an either predominantly social or predominantly ethical-normative phenomenon. ${ }^{6}$

Sebagian besar urusan kenegaraan, dalam kajian hukum telah menjadi norma etis yang diatur secara internasional. Setuju atau tidak, itulah yang terjadi. Bahwa setiap negara berdaulat ternyata dipaksa untuk melakukan persaingan bebas. Jika dianalogikan, siap atau tidak, sanggup atau tidak berenang, setiap negara dipaksa masuk ke lautan perdagangan bebas. Bagi

${ }^{5}$ Henry Campbell Black, Black's Law Dictionary, Third Edition, (Washington D.C.: St. Paul Minn. West Publishing Co. 1933), page.1643.

${ }^{6}$ Gerard Kreijen, State Failure, Sovereignty and Effectiveness: Legal Lessons from the Decolonization of Sub-Saharan Africa, (Leiden: Martinus Nijhoff Publishers, 2004), page. 8 
negara yang "bisa berenang", maka selamatlah ia, atau bahkan mereguk keuntungan, sedangkan negara yang "tidak bisa berenang", ia akan tenggelam, atau bahkan mati.

Kedaulatan juga berdekatan maknanya dengan politik. Apabila dikaitkan dengan politik, maka setiap manusia adalah "pekerja politik". Tidak seorangpun yang bukan "orang politik". Merujuk pada pendapat Aristoteles, setiap manusia adalah zoon politicon. Politik di sini diartikan sebagai sebuah ilmu tentang organisasi dan administrasi negara; aktivitasaktivitas atau profesi yang terlibat dalam bidang-bidang politik. Dalam pengertian dan khasanah keilmuan kita tentang politik, kata politik diserap begitu saja dari kata bahasa Inggris "Politics" yang dalam Black Law Dictionary diberi pengertian sebagai: 1) Thescience of the organization and administration of the state; and 2) The activity or profession of engaging in political affairs. ${ }^{7}$

Politik diartikan sebagai ilmu tentang organisasi negara dan bagaimana negara dijalankan. Di sinilah berkelindan antara hukum dan politik. Hukum membuat aturan main, sedangkan politik mengisinya dengan orang-orang dan alat-alat yang akan bekerja dalam negara itu. Thommas Hobbes menggambarkan kelindan ini dengan ungkapannya yang gamblang:

"The true and perspicuous explication of the Elements of Laws, Natural and Politic, which is my present scope, dependentn upon the knowledge of what is human nature, what is a body politic, and what it is we call a law. Concerning which points, as the writings of men from antiquity downward have still increased, so also have the doubts and controversies concerning the same, and seeing that true knowledge begetno doubt, nor controversy, but knowledge; it is manifest from the present controversies, that they which have heretofore written thereof, have not well understood their own subject." 8

Hobbes, dengan demikian mengungkapkan bahwa penjelasan yang benar dan mudah dipahami mengenai Unsur Hukum, Alam dan Politik, terikat (dependen) pada pengetahuan tentang sifat dasar manusia, apa itu lembaga politik, dan apa yang kita sebut hukum. Ia berpendapat bahwa konsep masing-masing orang dapat saja berbeda, sehingga keraguan dan kontroversi adalah sebuah keniscayaan. Pengetahuan yang dipahami secara benar akan memperanakkan kepastian.

Dari pernyataan ini, jelaslah bahwa pemahaman yang berbeda mengenai objek yang sama akan melahirkan keraguan dan kontroversi. Hal

\footnotetext{
${ }^{7}$ Bryan A. Garner, Black's Law Dictionary, Eight Edition, (St. Paul: West a Thomson, 2004), page. 1197.

${ }^{8}$ Thommas Hobbes, The Elements of Law Natural and Politic, (Cambridge, UK: Cambridge University Press, 1982), hlm. 3.
} 
ini adalah khas sifat dasar manusia dan pembawaan alamnya. Oleh karena itu penting untuk menyamakan konsep, walaupun persepsi setiap orang tentu tidak dapat diseragamkan. Persepsi tentang apakah negara tetap berdaulat, sedangkan ia dapat saja "dipaksa" untuk mengikuti aturan internasional layak dipertanyakan. Dalam konteks MEA 2015, misalnya, dapatkah Indonesia menolaknya? Apakah Malaysia bisa? Jika tidak bisa, benarkah negara itu berdaulat?

Politik dalam kajian ini dipahami sebagai cara bagaimana negara menyejahterakan rakyatnya. Itulah cita yang memang merupakan tujuan berdirinya negara ini. Kita juga harus memahami secara rinci dan presisi (distinct) tentang di mana letak politik dan kedaulatan dalam bernegara. Jadi, bertambah lagi kelindannya: politik, hukum, kedaulatan. Jika kita "gagal" meletakkannya dalam kedudukannya yang tepat, maka gagal pula konsep yang dibangun. Jadi, politik itu adalah metode yang dipilih dalam rangka mencapai tujuan negara, sedangkan kedaulatan merupakan prasyarat berdirinya suatu negara. Hukum berada di tengah sekaligus di luar. Ia menjadi semacam tugu dan pagar yang dengannya politik dan kedaulatan tidak saling "berebut lahan" meskipun berada dalam wilayah yang sama. Tugu adalah penanda arah, sedangkan pagar adalah batas-batas yang dengannya seluruh konsep menjadi terkurung.

\section{Konsepsi tentang Negara}

Literatur-literatur tentang hukum, politik, ekonomi, dan sosial, pendeknya seluruh ilmu yang kemudian kita kategorikan sebagai ilmu sosial $^{9}$, dibangun di atas filosofi bahwa negara itu ada. Kalau negara itu tidak diasumsikan sebagai "ada", maka runtuhlah seluruh bangunan lainnya yang disandarkan pada negara itu. Kemudian, yang ada hanya sekelompok manusia saja: tanpa negara, tak perlu politik, sedang hukum adalah kebiasaan perilaku mereka yang sama-sama mereka pegang teguh.

Jadi, negara itu harus ada dengan segala persyaratan yuridisnya yang tergambar dari falsafah hidup negara tersebut. Indonesia, memiliki nilai tersebut yang kita sebut dengan Pancasila. Lebih mudah, kita cermati Sila Kelima Pancasila, "Keadilan Sosial Bagi Seluruh Rakyat Indonesia". Inilah yang disebut Ekonomi Pancasila. Bahwa negara Indonesia diselenggarakan dalam rangka mencapai keadilan sosial bagi seluruh rakyat, tanpa kecuali.

Tantangan negara kesejahteraan diuji dengan penentuan pilihan kebijakan, apakah kebijakan yang dipilih akan membawa kesejahteraan bagi rakyat, atau sebalikya justru menyengsarakan rakyat. Memasuki hutan

\footnotetext{
${ }^{9}$ Dikotomi tentang ilmu sosial dan ilmu alam berangkat dari objek dan metode yang dipakai untuk memverifikasi ilmu tersebut. Kebenaran ilmu pasti dianggap mutlak, sedangkan ilmu sosial kebenarannya nisbi.
} 
belantara yang terdapat macan yang siap menerkam tanpa persenjataan yang cukup sama saja dengan bunuh diri. Untuk itu, negara memainkan peranan penting. Prasyarat yang menjadi prakondisi sebelum memasuki era perdagangan bebas harus dipersiapkan.

Secara klasik, kalau kita flash back lagi tentang teori terjadinya sebuah negara, maka teori JJ. Rousseau tentang "teori kontrak sosial" barangkali adalah teori yang paling dapat diterima oleh logika manusia modern. Bahwa negara terbentuk dari adanya perjanjian sosial (du Contract Social) di antara warga yang mendiami suatu wilayah tertentu. Kemudian, perjanjian/kontrak tersebut menjadi suatu sistem yang ajeg dan dipercaya serta diamalkan sampai sekarang. Perjanjian tersebut dapat saja berisi tentang tata cara kehidupan yang mereka anut, bagaimana hukum ditegakkan untuk menjaga kedamaian, dan bagaimana sistem politik dijalankan untuk memilih pemimpin di antara mereka. Pemimpin negara yang kita sebut pemerintah itulah yang dipercaya rakyat mencapai kehidupan yang sejahtera. Negara bertugas melindungi warganya.

Bila dikaitkan dengan negara, maka konsep perlindungan dapat didekati dengan konsep yang dikemukakan oleh Abdul Hakim Garuda Nusantara ${ }^{10}$ bahwa bagaimanapun juga hukum di Indonesia harus mengacu pada cita-cita masyarakat bangsa yakni tegaknya negara hukum yang demokratis dan berkeadilan sosial. Dalam konteks negara hukum, hal ini dilakukan demi mencapai kesejahteraan bersama bagi seluruh rakyat dalam pengertian yang sebenarnya, sebagai perwujudan masyarakat adil dan makmur. $^{11}$

Konsep negara seperti ini sejalan dengan pengertian negara hukum kesejahteraan, yang dalam berbagai literatur disebut dengan istilah yang berbeda-beda, antara lain welfare state atau social service state. ${ }^{12}$ Satjipto Rahardjo menyebut negara jenis ini dengan istilah "negara hukum yang membahagiakan rakyatnya". ${ }^{13}$ Jika dalam negara hukum klasik fungsi negara hanya sebagai "penjaga malam" (nachtwakkerstaat), maka negara hukum modern bertujuan untuk mewujudkan kesejahteraan rakyatnya. Negara hukum modern bersifat aktif, tidak dapat dipisahkan dari rakyatnya (staatsbemoeienis), mengedepankan penetapan tujuan (doelstelling) daripada penetapan norma (normstelling), mengedepankan rencana (plan) daripada

\footnotetext{
${ }^{10}$ Llihat Machfud M.D., Membangun Politik Hukum, Menegakkan Konstitusi, (Jakarta: Pustaka LP3ES), hlm.6.

${ }^{11}$ Sri Redjeki Hartono, Kapita Selekta Hukum Ekonomi, (Husni Syawali, edt.), (Bandung: Mandar Maju, 2000), hlm.3.

${ }^{12}$ S.F. Marbun, Peradilan Administrasi dan Upaya Administratif di Indonesia, (Yogyakarta: UII Press, 2003), hlm. 133.

${ }^{13}$ Satjipto Rahardjo, Negara Hukum yang Membahagiakan Rakyatnya, (Yogyakarta: Genta Press, 2008), hlm.100-119.
} 
instruksi (voorschrift), mengedepankan kebijakan (beleid) daripada pelaksanaan (uitvoering) atau penerapan (toepassing). ${ }^{14}$

\section{Upaya Perlindungan oleh Negara}

Makna leksikal dari kata "upaya" adalah usaha; ikhtiar (untuk mencapai suatu maksud, memecahkan persoalan, mencari jalan keluar, dsb). ${ }^{15}$ Upaya merupakan tindakan yang dilaksanakan dalam rangka menjalankan tugas dan fungsi. Dalam bidang pemerintahan, tugas pokok dan fungsi ini diberikan secara atributif oleh undang-undang. Upaya pemerintah dimulai dengan memberikan pengertian tentang pemerintah terlebih dahulu. Pemerintah (government) ditinjau dari pengertiannya berarti pengarahan dan administrasi yang berwenang atas kegiatan orang-orang dalam sebuah negara. $^{16}$

Istilah pemerintah dapat diklasifikasikan dalam pengertiannya yang sempit dan luas. Istilah pemerintah dalam arti luas meliputi seluruh kekuasaan negara yaitu kekuasaan legislatif, kekuasaan eksekutif dan kekuasaan yudikatif. Pengertian pemerintah dalam arti sempit hanya meliputi kekuasaan eksekutif saja. Kata pemerintah dalam persepektif hukum administrasi negara sama dengan administrasi negara, yang dalam bahasa Belanda dikenal dengan sebutan bestuur. ${ }^{17}$

Hadjon menulis bahwa kepustakaan bahasa Belanda mengartikan administrasi dalam istilah administratief recht dengan administrare/ besturen yang mengandung pengertian fungsional dan institusional/ struktural. Fungsi bestuur berarti keseluruhan organ pemerintah. Lingkungan Bestuur adalah lingkungan di luar lingkungan regelgeving (pembentukan peraturan) dan rechtspraak (peradilan). ${ }^{18}$

Negara hukum merupakan rumusan bagi negara yang secara sah menjalankan administrasi negara. Disebut demikian karena konsep ini merupakan antitesa dari negara yang berjalan atas dasar kekuasaan belaka. Negara hukum dimaksudkan agar penyelenggaraan negara berjalan dengan perencanaan dan kepastian, bukan atas dasar intuisi sesaat dari penguasanya. Dengan demikian, negara hukum akan menjamin hak-hak dari warganya, terlebih ketika mereka berhadapan dengan persaingan bebas.

\footnotetext{
${ }^{14}$ W. Riawan Tjandra, Hukum Administrasi Negara, (Yogyakarta: Universitas Atmajaya Press, 2008), hlm. 4-7.

${ }^{15}$ Kamus Besar Bahasa Indonesia (versi online di http://pusatbahasa.diknas.go.id/kbbi/)

${ }^{16}$ Tjandra, W. Riawan. Peradilan Tata Usaha Negara: Mendorong Terwujudnya Pemerintah yang Bersih dan Berwibawa, (Yogyakarta: Universitas Atmajaya, 2009), hlm.197.

${ }^{17}$ Ibid

${ }^{18}$ Phillipus M. Hadjon, Fungsi Normatif Hukum Administrasi dalam Mewujudkan Pemerintahan yang Bersih, Pidato Pengukuhan Jabatan Guru Besar dalam Ilmu Hukum Universitas Airlangga, Surabaya, 1994, hlm.3
} 
Adanya kasus-kasus tentang gagalnya negara dalam memberikan perlindungan bagi warganya, terutama dalam perdagangan bebas telah menjadi momok bagi rakyat. Rakyat yang tidak mampu bersaing dalam perdagangan bebas, pada akhirnya hanya menjadi penonton dan tidak memainkan peranan sebagai pemain yang dapat mereguk keuntungan.

Upaya negara (baca: pemerintah) dalam pemahaman ini merupakan wujud pengembanan fungsi dan peran pemerintah yang telah digariskan dalam peraturan perundang-undangan negara. Pemerintah dipahami sebagai organ yang menjalankan pemerintahan negara. Peran dan fungsi pemerintah ini timbul dari adanya wewenang yang melekat pada lembaga pemerintah sebagai alat negara. Wewenang ini timbul karena secara atributif diberi wewenang oleh undang-undang, atau merupakan wewenang delegatif.

Perlindungan warga ini akan berkaitan dengan peran negara dalam mewujudkan cita hukum Indonesia yang dirumuskan sebagai berikut: ${ }^{19}$

1. negara melindungi senap bangsa Indonesia dan seluruh tumpah darah Indonesia dengan berdasarkan atas persatuan;

2. negara hendak mewujudkan keadilan sosial bagi seluruh rakyat;

3. negara yang berkedaulatan rakyat, berdasar kerakyatan dan permusyawaratan perwakilan; dan

4. negara beradasar atas Ketuhanan Yang Maha Esa menurut dasar kemanusiaan yang adil dan beradab.

Cita perlindungan kepada segenap bangsa Indonesia tersebut menurut Thomas Aquinas merupakan prinsip keadilan komulatif, yaitu memberi perlindungan kepada semua warga bangsa. ${ }^{20}$ Wujud peran pemerintah ini antara lain melalui diplomasi dalam setiap perjanjian internasional yang berkenaan dengan perdagangan bebas, kompetisi terbuka, dsb.

Bila dikaitkan dengan konsep tanggung jawab negara untuk melindungi rakyatnya, maka hal ini telah diatur secara eksplisit dalam UUD Negara RI Tahun 1945 yang telah memberikan pengaturan yang sifatnya perlindungan (protection) dan promosi (promotion) terhadap kesejahteraan rakyat. Akan tetapi, sistem perundang-undangan yang dibangun tidak selalu konsisten, koheren dan berkoresponden dengan semangat yang ada dalam UUD NRI Tahun 1945.

Membaca konstitusi sebuah negara tidak hanya berhenti pada teks yang tercantum dalam konstitusi negara tersebut. Harus ada telaah yang lebih mendalam dalam membacanya agar ditemukan prinsip-prinsip yang terkandung di dalamnya. Tugas "melindungi" oleh negara terhadap rakyatnya merupakan tanggung jawab pemerintah sebagaimana diatur dalam Pasal 34. Berkaitan dengan hal tersebut Satjipto Rahardjo, mengkonsepsikan

\footnotetext{
${ }^{19}$ Yoan Nursari Simanjuntak, Hak Desain Industri (Sebuah Realitas Hukum dan Sosial), (Surabaya: Srikandi, 2005), hlm.214 - 215.

${ }^{20}$ Ibid.
} 
bahwa negara hukum Indonesia sebagai negara yang peduli atau negara dengan kepedulian. Konsepsi tersebut sangat tepat karena Pasal 34 ayat (2) menegaskan bahwa sebagai jaminan konstitusional maka negara wajib mengembangkan kebijakan kesejahteraan yang bersifat "affirmative action" bagi kepentingan warga masyarakatnya.

Bentuk perlindungan negara adalah dengan membuat regulasi yang dapat memproteksi warganya. Namun, hal ini tidak dapat dilakukan karena keterikatan setiap negara pada Konvensi Internasional, termasuk bahwa setiap negara tidak boleh melakukan hambatan (barrier) terhadap perdagangan. Kesiapan regulasi juga perlu dipertimbangkan dalam menghadapi MEA 2015 dan hal itu tidak boleh keluar dari cita-cita perlindungan negara terhadap warga.

Bentuk perlindungan lain adalah kesadaran bahwa Indonesia termasuk ke dalam negara yang masyarakatnya memiliki tingkat konsumsi yang tinggi. Perilaku konsumtif inilah yang menjadi penilaian negara lain yang menjadikan Indonesia sebagai pangsa pasar bagi setiap produk perdagangan barang dan jasanya. Regulasi tentang penggunaan produk dalam negeri, misalnya, dapat dijadikan pilihan kebijakan untuk "memproteksi" warga. Hal ini telah dilakukan melalui Inpres No. 6/2009 tentang Program Ekonomi Kreatif.

Dalam jangka panjang, kesejahteraan masyarakat akan coba dibangun dengan jalan peningkatan ekonomi. Dalam hal pengendalian barang masuk, Indonesia juga dapat menerapkan regulasi Pengetatan pengawasan penggunaan Surat Keterangan Asal barang (SKA) dari negara anggota MEA 2015.

Upaya lain yang dapat dilakukan adalah menciptakan perdagangan yang sehat dan iklim usaha yang kondusif; reformasi kebijakan pendukung investasi, pengembangan kawasan perdagangan bebas dan kawasan ekonomi khusus, dan peningkatan pelayanan perizinan perdagangan bagi dunia usaha. Selain itu, dapat dilakukan juga tindakan pengamanan produk dalam negeri dan pengawasan terhadap barang beredar dan jasa, serta dengan menerapkan Early Warning System terhadap kemungkinan terjadinya lonjakan impor. Hal ini dibarengi juga dengan peningkatan ekspor yang akan memperbesar volume perdagangan yang pada akhirnya akan menguntungkan neraca perdagangan. Penetapan UU Nomor 39 Tahun 2009 tentang Kawasan Ekonomi Khusus (KEK) dapat juga dipahami sebagai upaya pemerintah tersebut. Dengan kesiapan dan upaya negara ini, maka tugas negara dalam mencapai kesejahteraan warga akan mudah terwujud.

\section{Penutup}

Kajian ini dimulai dari pertanyaan tentang apakah pelaksanaan MEA 2015 akan bertentangan dengan konsep negara kesejahteraan? Negara masih 
dapat terus melaksanakan kewajibannya untuk mewujudkan kesejahteraan rakyat tanpa harus menghindar dari kesepakatan internasional yang dituangkan dalam MEA 2015. Upaya negara dalam hal ini antara lain dengan meningkatkan daya saing, meningkatkan volume ekspor, mengutamakan penggunaan barang/ jasa dalam negeri. Di bidang regulasi, perlu ditetapkan peraturan tentang tindakan pengamanan produk dalam negeri dan pengawasan terhadap barang beredar dan jasa, serta dengan menerapkan Early Warning System terhadap kemungkinan terjadinya lonjakan impor.

Negara boleh membuat kebijakan yang memberi proteksi kepada warganya dengan tetap memperhatikan asas non-diskriminasi. Proteksi yang dilakukan oleh negara dilakukan dengan memberikan batasan terhadap halhal apa saja yang dapat dilakukan dalam kerangka MEA dan apa saja yang bersifat tertutup. Dengan demikian, kedaulatan negara tidak dipertaruhkan hanya demi menjalankan kesepakatan internasional. Kedaulatan negara tetap berjalan dengan penuh, dengan tetap memperhatikan prinsip pergaulan internasional.

\section{Daftar Pustaka}

\section{A. Buku}

Garner, Bryan A., 2004, Black's Law Dictionary, Eight Edition, St. Paul: West a Thomson.

Kreijen, Gerard; Failure, State, 2004, Sovereignty and Effectiveness: Legal Lessons from the Decolonization of Sub-Saharan Africa, Leiden: Martinus Nijhoff Publishers.

Black, Henry Campbell, 1933, Black's Law Dictionary, Third Edition, Washington D.C.: St. Paul Minn. West Publishing Co.

M.D. Machfud, 2004, Membangun Politik Hukum, Menegakkan Konstitusi, Jakarta: Pustaka LP3ES.

Marbun, S.F., 2003, Peradilan Administrasi dan Upaya Administratif di Indonesia, Yogyakarta: UII Press.

Rahardjo, Satjipto, 2008, Negara Hukum yang Membahagiakan Rakyatnya, Yogyakarta: Genta Press.

Hartono, Sri Redjeki, 2000, Kapita Selekta Hukum Ekonomi, (Husni Syawali, edt.), Bandung: Mandar Maju.

Sudaryanto, 2007, Filsafat Politik Pancasila: Refleksi Atas Teks Perumusan Pancasila, Yogyakarta: Kepel Press

Hobbes, Thommas, 1982, The Elements of Law Natural and Politic, Cambridge, UK: Cambridge University Press. 
Tjandra, W. Riawan, 2009, Peradilan Tata Usaha Negara: Mendorong Terwujudnya Pemerintah yang Bersih dan Berwibawa, Yogyakarta: Universitas Atmajaya.

Tjandra, W. Riawan, 2008, Hukum Administrasi Negara, Yogyakarta: Universitas Atmajaya Press.

Simanjuntak, Yoan Nursari, 2005, Hak Desain Industri (Sebuah Realitas Hukum dan Sosial), Surabaya: Srikandi.

\section{B. Lain-lain}

Direktorat Kerjasama ASEAN Kemendag RI, "Kesiapan Indonesia Memasuki Masyarakat Ekonomi ASEAN di 2015", Presentasi dibawakan di Hotel Aryaduta, Jakarta, 13 Desember 2010.

Kamus Besar Bahasa Indonesia (versi online di http://pusatbahasa.diknas.go.id/kbbi/)

Hadjon, Phillipus M., 1994, Fungsi Normatif Hukum Administrasi dalam Mewujudkan Pemerintahan yang Bersih, Pidato Pengukuhan Jabatan Guru Besar dalam Ilmu Hukum Universitas Airlangga, Surabaya. 